\title{
Kajian Mineral Fraksi Pasir pada Andisol yang Berkembang dari Hasil Erupsi Gunung Tangkuban Parahu dan Gunung Patuha, Jawa Barat
}

\section{Rina Devnita, Mahfud Arifin, dan Ridha Hudaya}

\author{
Staff Pengajar Departemen Ilmu Tanah dan Sumberdaya Lahan Fakultas Pertanian \\ Universitas Padjadjaran \\ Jl. Raya Bandung Sumedang Km 21 Jatinangor \\ Korespondensi: rinabursi@yahoo.com
}

\begin{abstract}
Mineral content of the soil determines various properties including nutrient that can be released during the weathering process. The research to identify the minerals in Andisol developed from the eruption of Mt. Tangkuban Parahu and Mt. Patuha had been conducted to determine the minerals content in the sand fraction. This research was conducted in several steps: the field survey, soil sampling, and laboratory analysis. The field locations were in the forest of Cikole, Lembang, West Java derived from the eruption Mt. Tangkuban Parahu and in the forest of Patengan, Rancabali, West Java derived from the eruption of Mt. Patuha. Sand fraction was separated from silt and clay by wet sieving method, using the 50 micron siever. Microscopic observation for identifying the minerals was done with polarization microscope to the color, luster, shape of grains and crystals, cleavage, hardness, transparency, translucent, and magnetic properties. The results showed that the sand fraction of Andisol derived from Mt. Tangkuban Parahu and Mt. Patuha had the mineral content as hypersthene, diopside, orthoclase, oligoclase, anorthite, andesine, hornblende, biotite, quartz, corundum, magnetite dan sulphur, showed that the weathering those minerals can contribute some nutrients like $\mathrm{Mg}, \mathrm{Ca}, \mathrm{K} \mathrm{Fe}$, and $\mathrm{S}$ to the soil
\end{abstract}

Key words: hyperstene, diopside, anorthite, hornblende, biotite

\section{PENDAHULUAN}

Indonesia mempunyai 129 gunungapi aktif atau $13 \%$ dari gunungapi di dunia (Sudradjat, 1992; 2009). Gunungapi tersebut dalam aktivitasnya menyemburkan abu yang selanjutnya akan menjadi bahan induk dari tanah abu gunungapi, sehingga pada daerah bergunungapi ditemukan tanah yang dalam Taksonomi Tanah (Soil Survey Staff, 2014) dapat dikelompokkan dalam ordo Andisol. Luas Andisol di Indonesia sekitar 5.836 juta ha atau 3,4\% luas daratan Indonesia (Puslitbangtanak, 2001). Andisol hanya menempati sebagian kecil dari luas daratan, akan tetapi Andisol mempunyai peran penting dalam pertanian karena termasuk tanah yang produktif untuk berbagai tanaman hortikultura dan perkebunan.

Pulau Jawa memiliki 35 gunungapi aktif dan 19 di antaranya terdapat di Jawa Barat.
Gunung Tangkuban Parahu dan Gunung Patuha merupakan dua dari gunungapi aktif di Jawa Barat dan daerah di sekitarnya merupakan daerah sebaran Andisol (Arifin, 1994; Devnita et al, 2010). Bahan klastika yang berasal dari letusan gunungapi menambahkan mineral mudah lapuk ke dalam tanah, yang melapuk dengan cepat dan melepaskan berbagai hara yang diperlukan tanaman (Parfitt dan Wilson, 2008). Potensi hara tersebut dapat tercermin dari mineral pada fraksi pasirnya.

Komposisi mineral pada horison tanah juga menunjukkan homogenitas atau heterogenitas horison, cadangan hara, tingkat pelapukan, asal mineral liat, sifat tanah yang terbentuk, penciri utama famili tanah, dan menentukan jenis bahan induk tanah (Hardjowigeno, 2003). Komposisi mineral fraksi pasir menarik untuk diamati karena 
terkait dengan potensi hara yang dilepas ke dalam tanah pada proses pelapukannya. Identifikasi mineral fraksi pasir pada Andisol yang berkembang dari hasil erupsi G. Tangkuban Parahu dan G. Patuha diharapkan akan memberikan informasi mengenai potensi sumbangan hara mineral-mineral tersebut dan melengkapi pemahaman mengenai bahan induk Andisol.

\section{METODE PENELITIAN}

Bahan penelitian ini adalah fraksi pasir yang diperoleh dari setiap horison pada profil Andisol di hutan pinus Desa Cikole, Kecamatan Lembang, Kabupaten Bandung Barat, Jawa Barat, yang berada pada sisi selatan G. Tangkuban Parahu serta Desa Patengan, Kecamatan Rancabali, Kabupaten Bandung Barat, Jawa Barat, yang berada pada sisi utara G. Patuha.

Alat yang digunakan di lapangan antara lain peta geologi lembar Bandung skala 1 : 100.000 (Silitonga, 2003) dan peta geologi lembar Sindang Barang skala $1: 300.000$ (Koesmono, 1976). Peta lain yang digunakan adalah peta tanah (Bapeda, 2008a), penggunaan lahan (Bapeda, 2008b), topografi (Bapeda, 2008c) dan iklim (Bapeda, 2010).

Peralatan lapagan lainnya berupa kertas deskripsi, clinometer, kantong plastik, pisau, bor tanah (bor Belgia), meteran, label, kamera foto, Munsell Soil Color Chart dan GPS (Global Position System). Pengamatan di lapangan berpedoman pada National Soil Survey Center (2002). Peralatan laboratorium adalah alat untuk analisis tekstur dengan metode pengayakan basah (Van Reeuwijk, 1992) dan mikroskop polarisasi untuk pengamatan mineral (Mange and Mauver, 1992).

Penelitian dimulai dengan menginventarisasi peta untuk menentukan lokasi pengamatan dan pengambilan sampel tanah dengan cara menumpangsusunkan (overlay) petapeta yang ada sehingga menghasilkan peta kombinasi penyebaran bahan induk dan formasi geologi dengan tanah dan penggu- naan lahan serta kemiringan yang sesuai untuk pembuatan profil tanah yaitu tanah ordo Andisol, dengan bahan induk hasil erupsi gunungapi pada areal hutan alami dengan kemiringan 8-15\%.

Sampel tanah diambil pada setiap horison yang ada pada profil. Sampel tanah selanjutnya dipisahkan fraksi pasirnya di laboratorium. Fraksi pasir ini diperoleh melalui analisis tekstur dengan terlebih dahulu menggunakan peroksida $\left(\mathrm{H}_{2} \mathrm{O}_{2}\right)$ untuk menghilangkan bahan organik, dan partikel tanah diperoleh melalui pengayakan dengan saringan berukuran $2 \mathrm{~mm}$ untuk mendapatkan partikel pasir. Pemisahan fraksi pasir dari debu dan liat dilakukan dengan pengayakan menggunakan saringan berukuran 50 mikron (Van Reeuwijk, 1992). Identifikasi mineral dilakukan dengan mikros-kop polarisasi mempedomani Mange and Mauver (1992).

\section{HASIL DAN PEMBAHASAN}

\subsection{Informasi lokasi penelitian}

Lokasi penelitian adalah Desa Cikole yang berada di lereng selatan G. Tangkuban Parahu (TPR) dan Desa Patengan yang berada lereng utara G. Patuha (PTH). Desa Cikole berkembang dari hasil erupsi G. Tangkuban Parahu, berbahan induk andesit berumur Holosen berupa tuf pasir kristal hornblende, lahar lapuk kemerahan, lapisan lapili dan breksi dari G. Dano dan G. Tangkuban Parahu yang disimbolkan dengan Qyd (Silitonga, 2003). Profil tanah berada pada daerah dengan topografi $8-15 \%$.

Fisiografi dan deskripsi profil TPR ditampilkan pada Tabel 1 dan 2. Desa Patengan berkembang dari induk lava berkomposisi andesitik dan andesit-basaltik berupa lahar yang mengandung tuf pasiran abu-abu dan plagioklas yang disimbolkan dengan Qv $(\mathrm{p}, \mathrm{l})$ dari G. Patuha berumur Holosen (Koesmono, 1976). Profil tanah berada pada daerah dengan topografi 8-15\%. Fisiografi dan deskripsi profl PTH ditampilkan pada Tabel 3 dan 4 . 
Tabel 1 Fisiografi Profil TPR

\begin{tabular}{|c|c|c|}
\hline $\begin{array}{l}\text { Lokasi } \\
\text { Administrasi }\end{array}$ & : & $\begin{array}{l}\text { Desa Cikole, Kecamatan } \\
\text { Lembang, Kabupaten Bandung } \\
\text { Barat }\end{array}$ \\
\hline Bahan induk & & $\begin{array}{l}\text { Tuf pasir G. Dano dan } \\
\text { GTangkuban Parahu }\end{array}$ \\
\hline \multirow[t]{2}{*}{ Koordinat } & & $X=107^{0} 38^{\prime} 57$ \\
\hline & & $Y=06^{0} 47^{\prime} 07^{\prime \prime}$ \\
\hline Elevasi & : & $1.300 \mathrm{~m} \mathrm{dpl}$ \\
\hline Kemiringan & : & $12 \%$ \\
\hline Drainase & : & Baik \\
\hline Vegetasi & : & $\begin{array}{l}\text { Pinus (Pinus mercusii), Rumput } \\
\text { Gajah (Pueraria phaseoloides) }\end{array}$ \\
\hline $\begin{array}{l}\text { Klasifikasi } \\
\text { tanah }\end{array}$ & & $\begin{array}{l}\text { Cikole, Typic Hapludands, } \\
\text { besar, amorfik, isohipertermik }\end{array}$ \\
\hline Iklim & & $\begin{array}{l}\text { Regim kelembapan tanah udik } \\
\text { Regim temperatur tanah } \\
\text { isohipertermik }\end{array}$ \\
\hline
\end{tabular}

Informasi yang diperoleh dari fisiografi pada Tabel 1 dan 3 menunjukkan bahwa Andisol pada kedua lokasi adalah Andisol dataran tinggi yang berada pada ketinggian lebih dari $1200 \mathrm{~m}$ dan berkembang di bawah vegetasi hutan pada regim kelembaban udik serta regim temperatur isohipertermik (TPR) dan isotermik (PTH).

Deskripsi profil pada Tabel 2 dan 4 menunjukkan bahwa Andisol pada kedua lokasi mempunyai susunan horizon yang lengkap Ap, Bw, $2 \mathrm{Ab}, 2 \mathrm{Bw}$ dan $2 \mathrm{BC}$ (TPR) dan Ap, Bw, BC, C, 2 Ab, 2 CB, 2 C dan R (PTH). Adanya horison A dan Bw menunjukkan tanahnya telah berkembang membentuk solum dengan horison $\mathrm{A}$ dan $\mathrm{B}$, meskipun perkembangan horison $\mathrm{B}$ masih lemah (Bw).

Tabel 2 Deskripsi Profil TPR

\begin{tabular}{|c|c|c|}
\hline $\begin{array}{l}\text { Kedalaman } \\
\text { (cm) }\end{array}$ & Horison & Uraian \\
\hline $0-14$ & Ap1 & $\begin{array}{l}\text { Coklat kekuning-kuningan (10YR 5/6); lempung berdebu; remah, sangat halus, } \\
\text { lemah, sangat gembur; pori makro sedikit, meso banyak dan mikro banyak; akar } \\
\text { besar banyak, akar medium sedang dan akar kecil banyak; pH 5; batas horison baur, } \\
\text { rata }\end{array}$ \\
\hline $14-22$ & Ap2 & $\begin{array}{l}\text { Coklat gelap kekuning-kuningan (10YR 4/6); lempung berdebu; remah, sangat halus, } \\
\text { lemah, sangat gembur; pori makro sedikit, meso banyak dan mikro banyak; akar } \\
\text { besar tidak ada, akar medium banyak dan akar kecil ; pH 5; batas horison baur, rata }\end{array}$ \\
\hline $22-48$ & Ap3 & $\begin{array}{l}\text { Coklat gelap kekuning-kuningan (10YR 4/4); lempung berdebu; remah, halus, agak } \\
\text { lemah, gembur; pori makro sedikit, meso banyak dan mikro banyak; akar besar } \\
\text { sedikit, akar medium banyak dan akar kecil banyak; pH 5; batas horison baur, rata }\end{array}$ \\
\hline $48-58$ & Bw & $\begin{array}{l}\text { Coklat gelap kekuning-kuningan (10YR 3/4); lempung berdebu; gumpal bersudut, } \\
\text { halus, agak lemah, gembur; pori makro sedikit, meso banyak dan mikro banyak; akar } \\
\text { besar sedikit, akar medium sedikit, akar kecil sedikit; pH 5; batas horison jelas, rata }\end{array}$ \\
\hline $58-87$ & $2 \mathrm{Ab} 1$ & $\begin{array}{l}\text { Coklat sangat gelap (10YR 2/2); debu; remah, halus, lemah, sangat gembur; pori } \\
\text { makro sedikit, meso banyak dan mikro banyak; akar besar tidak ada, akar medium } \\
\text { sedikit dan akar kecil banyak; pH 5.5; batas horison baur, rata }\end{array}$ \\
\hline $87-110$ & $2 \mathrm{Ab} 2$ & $\begin{array}{l}\text { Hitam (10YR 2/1); debu; remah, halus, lemah, gembur; pori makro sedikit, meso } \\
\text { banyak, dan mikro; akar besar tidak ada, akar medium sedang and akar kecil banyak; } \\
\text { pH 6; batas horison baur, rata }\end{array}$ \\
\hline $110-119$ & $2 \mathrm{BA}$ & $\begin{array}{l}\text { Coklat sangat gelap (10YR 2/3); debu; gumpal bersudut, halus, lemah, gembur; pori } \\
\text { makro sedikit, meso banyak dan mikro banyak; akar besar tidak, akar medium sedikit } \\
\text { dan akar kecil sedikit; pH 5; batas horison jelas, rata }\end{array}$ \\
\hline $119-144$ & 2 Bw1 & $\begin{array}{l}\text { Coklat gelap (10YR 3/3); debu; gumpal bersudut, medium, sedang, teguh; pori makro } \\
\text { sedikit, meso banyak dan mikro banyak; akar besar tidak ada, akar medium sedikit } \\
\text { dan akar kecil sedang, pH 5; batas horison jelas, rata }\end{array}$ \\
\hline $144-162$ & 2 Bw2 & $\begin{array}{l}\text { Coklat gelap kekuning-kuningan (10YR } 3 / 6) \text {; debu; gumpal bersudut, medium, } \\
\text { sedang, teguh; pori makro sedikit, meso banyak dan mikro banyak; akar besar tidak } \\
\text { ada, akar medium tidak ada dan akar kecil tidak ada; } \mathrm{pH} 5 \text {; batas horison baur, rata }\end{array}$ \\
\hline $162-200$ & $2 \mathrm{BC}$ & $\begin{array}{l}\text { Coklat gelap kekuning-kuningan (10YR 4/6); debu; gumpal bersudut, medium, keras, } \\
\text { teguh; pori makro sedikit, meso banyak dan mikro banyak; akar besar sedikit, akar } \\
\text { medium sedikit dan akar kecil sedikit; pH } 4\end{array}$ \\
\hline
\end{tabular}


Tabel 3 Fisiografi Profil PTH

\begin{tabular}{|c|c|c|}
\hline Lokasi Administrasi & : & Desa Patengan, Kecamatan Rancabali, Kabupaten Bandung \\
\hline Bahan induk & : & Lava dan lahar G. Patuha \\
\hline \multirow[t]{2}{*}{ Koordinat } & & $X=107^{0} 23^{\prime} 35^{\prime \prime}$ \\
\hline & & $Y=07^{0} 08^{\prime} 40^{\prime \prime}$ \\
\hline Elevasi & : & $1.791 \mathrm{~m} \mathrm{dpl}$ \\
\hline Kemiringan & : & $8 \%$ \\
\hline Drainase & : & Baik \\
\hline Vegetasi & : & Kayu Putih (Melaleuca leucadendron) Alang-alang (Imperata cylindria) \\
\hline Klasifikasi tanah & : & Patengan, Typic Hapludands, besar, amorfik, isotermik \\
\hline \multirow[t]{2}{*}{ Iklim } & : & Regim kelembapan tanah udik \\
\hline & & Regim temperatur tanah isotermik \\
\hline
\end{tabular}

Tabel 4 Deskripsi Profil PTH

\begin{tabular}{|c|c|c|}
\hline $\begin{array}{l}\text { Kedalaman } \\
\quad(\mathrm{cm})\end{array}$ & Horison & Uraian \\
\hline $0-11$ & Ap1 & $\begin{array}{l}\text { Coklat gelap (10YR 3/3); debu; remah, sedang, lemah, sangat gembur; pori } \\
\text { makro banyak, meso banyak dan mikro banyak; akar besar banyak, akar } \\
\text { sedang banyak dan akar kecil banyak; pH 5; batas horison jelas, rata }\end{array}$ \\
\hline $11-19$ & Ap2 & $\begin{array}{l}\text { Coklat keabu-abuan gelap (10YR } 3 / 4) \text {; debu; remah, sedang, lemah, sangat } \\
\text { gembur; pori makro banyak, meso banyak dan mikro banyak; akar besar } \\
\text { banyak, akar sedang banyak dan akar kecil banyak; pH 5; batas horison jelas, } \\
\text { rata }\end{array}$ \\
\hline $19-39$ & Ap3 & $\begin{array}{l}\text { Coklat gelap kekuning-kuningan (10YR } 3 / 6) \text {; debu; remah, sedang, lemah, } \\
\text { sangat gembur; pori makro banyak, meso banyak dan mikro banyak; akar } \\
\text { besar banyak, akar sedang banyak dan akar kecil banyak; pH 5; batas horison } \\
\text { jelas, rata }\end{array}$ \\
\hline $39-67$ & Bw & $\begin{array}{l}\text { Coklat gelap kekuning-kuningan (10YR 4/6); debu; remah, sedang, lemah, } \\
\text { gembur, banyak fragmen batuan volkanik; pori makro sedikit, meso banyak } \\
\text { dan mikro banyak; akar besar banyak, akar sedang banyak dan akar kecil } \\
\text { banyak; pH 5; batas horison jelas, rata }\end{array}$ \\
\hline $67-85 / 95$ & $\mathrm{BC}$ & $\begin{array}{l}\text { Coklat kekuning-kuningan (10YR 5/6); debu; gumpal bersudut, sedang, lemah, } \\
\text { teguh, banyak fragmen batuan volkanik; pori makro sedikit, meso sedikit dan } \\
\text { mikro sedikit; akar besar banyak, akar sedang banyak dan akar kecil banyak; } \\
\text { pH 5; batas horison jelas, berombak }\end{array}$ \\
\hline $85 / 95-102$ & $\mathrm{C}$ & $\begin{array}{l}\text { Coklat kekuning-kuningan (10YR } 5 / 8) \text {; debu; gumpal bersudut, halus, sedang, } \\
\text { lemah, teguh, banyak fragmen batuan volkan; pori makro sedikit, meso sedikit } \\
\text { dan mikro banyak; akar besar sedikit, akar medium sedang dan akar kecil } \\
\text { sedang; pH 4; batas horison jelas, berombak }\end{array}$ \\
\hline $102-125$ & $2 \mathrm{Ab}$ & $\begin{array}{l}\text { Coklat gelap kekuning-kuningan (10YR 4/4); debu; gumpal bersudut, halus, } \\
\text { sedang, teguh; pori makro sedikit, meso sedikit dan mikro sedikit; akar besar } \\
\text { tidak ada, akar sedang tidak ada dan akar kecil sedikit; pH 4; batas horison } \\
\text { jelas, rata }\end{array}$ \\
\hline $125-141$ & $2 \mathrm{CB}$ & $\begin{array}{l}\text { Coklat gelap kekuning-kuningan (10YR 4/6); debu; gumpal bersudut, halus, } \\
\text { sedang, gembur, banyak fragmen batuan volkanik; pori makro sedikit, meso } \\
\text { sedikit dan mikro sedikit; akar besar tidak ada, akar sedang tidak ada dan akar } \\
\text { kecil sedikit; pH 4; batas horison jelas, rata }\end{array}$ \\
\hline $141-157$ & $2 \mathrm{C}$ & $\begin{array}{l}\text { Coklat gelap kekuning-kuningan (10YR 3/6); debu; remah, halus, sedang, } \\
\text { gembur ; pori makro sedikit, meso sedikit dan mikro sedikit; akar besar tidak } \\
\text { ada, akar sedang tidak ada dan akar kecil sedikit; pH 5; batas horison jelas, } \\
\text { rata }\end{array}$ \\
\hline $157-200$ & $\mathrm{R}$ & Tidak ada uraian untuk horison $\mathrm{R}$ \\
\hline
\end{tabular}


Hal yang menarik dari kedua profil adalah ditemukannya horison tertimbun (2 Ab). Adanya horizon ini menunjukkan terdapatnya lithologic discontinuity (litologi yang tidak berkelanjutan) yang merupakan informasi bahwa tanah pada profil tersebut berkembang dari lebih satu sumber erupsi bahan induk. Adanya lithologic discontinuity secara morfologi antara lain terlihat dari warna tanah yang berubah kembali menjadi gelap. Hal tersebut terjadi pada horison A di kedalaman tertentu, yang teridentifikasi dari value dan chroma yang kembali kecil.

Profil TPR memperlihatkan nilai value dan chroma mengecil menjadi 10YR 2/2 pada kedalaman 58-87 $\mathrm{cm}$ dibandingkan horison $48-58 \mathrm{~cm}$ di atasnya yang mempunyai nilai 10YR 3/4. Profil PTH menunjukkan perubahan tersebut pada kedalaman $102-125 \mathrm{~cm}$ dengan nilai 10YR 4/4 yang lebih kecil dibandingkan 10YR 5/8 pada horison 85/95-102 $\mathrm{cm}$ di atasnya. Adanya lithologic discontinuity ini menunjukkan tanah tersebut berkembang dari beberapa periode erupsi gunungapi dan merupakan hal yang lazim pada Andisol meskipun tidak semua Andisol memiliki lithologic discontiuty.

Lihologic discontinuity tidak hanya dijumpai pada Andisol saja tetapi dapat ditemukan pada ordo tanah lainnya, Ande dan Senjobi
(2002) menemukannya pada ordo Inceptisol, Ultisol dan Entisol. Ande dan Senjobi (2002) juga menambahkan bahwa lithologic discontinuity tidak hanya dapat diamati melalui perubahan warna, tetapi juga melalui perbedaan tekstur dan struktur. Weindorf et. al. (2015), lebih lanjut mengemukakan bahwa adanya lithologic discontinuity dapat diungkapkan dengan menggunakan Portable X-ray Fluorescence Spectrometry and Visible NearInfrared Diffuse Reflectance Spectroscopy.

\subsection{Kajian mineral faksi pasir}

Hasil analisis fraksi pasir pada profil TPR dan profil PTH ditampilkan pada Tabel 5 dan 6. Penampakan mikroskopis dan deskripsi mineral yang ditemukan pada profil TPR dan PTH diamati di bawah mikroskop ditampilkan pada Tabel 7. Hasil analisis tersebut menunjukkan bahwa pada profil TPR terdapat sepuluh jenis mineral yaitu hiperstin, diopsid, ortoklas, plagioklas, anortit, hornblende, biotit, kuarsa magnetit dan korondum. Mineral yang sama (hiperstin, diopsid, ortoklas, plagioklas, anortit, biotit, kuarsa, magnetit, dan korondum) juga ditemukan pada profil PTH. Meskipun demikian pada PTH tidak ditemukan hornblende, melainkan andesin. Mineral sulfur juga ditemukan pada PTH dan tidak terdapat pada TPR.

Tabel 5 Kandungan mineral fraksi pasir pada Profil TPR

\begin{tabular}{llcccccccccc}
\hline \multirow{2}{*}{ No } & \multicolumn{10}{c}{ Mineral } & \multicolumn{10}{c}{ Horison } \\
\cline { 2 - 11 } & $\mathrm{Ap}_{1}$ & $\mathrm{Ap}_{2}$ & $\mathrm{Ap}_{3}$ & $\mathrm{Bw}$ & $2 \mathrm{Ab}_{1}$ & $2 \mathrm{Ab}_{2}$ & $2 \mathrm{BA}$ & $2 \mathrm{Bw}_{1}$ & $2 \mathrm{Bw}_{2}$ & $2 \mathrm{BC}$ \\
\hline 1 & Hiperstin & $\sqrt{ }$ & $\sqrt{ }$ & $\sqrt{ }$ & $\sqrt{ }$ & - & - & - & $\sqrt{ }$ & $\sqrt{ }$ & $\sqrt{ }$ \\
2 & Diopsid & $\sqrt{ }$ & $\sqrt{ }$ & $\sqrt{ }$ & $\sqrt{ }$ & $\sqrt{ }$ & $\sqrt{ }$ & $\sqrt{ }$ & $\sqrt{ }$ & $\sqrt{ }$ & $\sqrt{ }$ \\
3 & Ortoklas & $\sqrt{ }$ & $\sqrt{ }$ & $\sqrt{ }$ & $\sqrt{ }$ & $\sqrt{ }$ & $\sqrt{ }$ & - & - & - & $\sqrt{ }$ \\
4 & Oligoklas & $\sqrt{ }$ & $\sqrt{ }$ & $\sqrt{ }$ & - & $\sqrt{ }$ & - & - & - & - & - \\
5 & Anortit & $\sqrt{ }$ & $\sqrt{ }$ & - & $\sqrt{ }$ & - & $\sqrt{ }$ & $\sqrt{ }$ & $\sqrt{ }$ & $\sqrt{ }$ & $\sqrt{ }$ \\
6 & Hornblende & $\sqrt{ }$ & $\sqrt{ }$ & $\sqrt{ }$ & $\sqrt{ }$ & $\sqrt{ }$ & $\sqrt{ }$ & $\sqrt{ }$ & $\sqrt{ }$ & $\sqrt{ }$ & $\sqrt{ }$ \\
7 & Biotit & $\sqrt{ }$ & $\sqrt{ }$ & $\sqrt{ }$ & $\sqrt{ }$ & $\sqrt{ }$ & $\sqrt{ }$ & $\sqrt{ }$ & $\sqrt{ }$ & $\sqrt{ }$ & $\sqrt{ }$ \\
8 & Kuarsa & $\sqrt{ }$ & $\sqrt{ }$ & $\sqrt{ }$ & $\sqrt{ }$ & $\sqrt{ }$ & $\sqrt{ }$ & $\sqrt{ }$ & $\sqrt{ }$ & $\sqrt{ }$ & $\sqrt{ }$ \\
9 & Korondum & $\sqrt{ }$ & $\sqrt{ }$ & - & $\sqrt{ }$ & $\sqrt{ }$ & $\sqrt{ }$ & $\sqrt{ }$ & $\sqrt{ }$ & $\sqrt{ }$ & $\sqrt{ }$ \\
10 & Magnetit & $\sqrt{ }$ & $\sqrt{ }$ & $\sqrt{ }$ & $\sqrt{ }$ & $\sqrt{ }$ & $\sqrt{ }$ & $\sqrt{ }$ & $\sqrt{ }$ & $\sqrt{ }$ & $\sqrt{ }$ \\
\hline
\end{tabular}


Tabel 6 Kandungan mineral fraksi pasir pada profil PTH

\begin{tabular}{cccccccccccc}
\hline \multirow{2}{*}{ No } & \multirow{2}{*}{ Mineral } & \multicolumn{10}{c}{ Horison } \\
\cline { 2 - 10 } & $\mathrm{Ap}_{1}$ & $\mathrm{Ap}_{2}$ & $\mathrm{Ap}_{3}$ & $\mathrm{Bw}$ & $\mathrm{C}$ & $\mathrm{Ab}_{1}$ & $\mathrm{Ab}_{2}$ & $2 \mathrm{CB}$ & $2 \mathrm{C}$ & $\mathrm{R}$ \\
\hline 1 & Hiperstin & $\sqrt{ }$ & $\sqrt{ }$ & $\sqrt{ }$ & - & $\sqrt{ }$ & $\sqrt{ }$ & $\sqrt{ }$ & $\sqrt{ }$ & $\sqrt{ }$ & - \\
2 & Diopsid & $\sqrt{ }$ & $\sqrt{ }$ & $\sqrt{ }$ & $\sqrt{ }$ & $\sqrt{ }$ & $\sqrt{ }$ & $\sqrt{ }$ & $\sqrt{ }$ & $\sqrt{ }$ & - \\
3 & Ortoklas & $\sqrt{ }$ & $\sqrt{ }$ & - & - & - & - & $\sqrt{ }$ & $\sqrt{ }$ & $\sqrt{ }$ & - \\
4 & Oligoklas & $\sqrt{ }$ & - & - & - & - & - & - & - & - & - \\
5 & Anortit & - & - & - & - & - & - & - & $\sqrt{ }$ & $\sqrt{ }$ & - \\
6 & Andesine & - & $\sqrt{ }$ & $\sqrt{ }$ & $\sqrt{ }$ & $\sqrt{ }$ & $\sqrt{ }$ & - & - & - & - \\
7 & Biotit & - & - & - & - & $\sqrt{ }$ & $\sqrt{ }$ & $\sqrt{ }$ & $\sqrt{ }$ & $\sqrt{ }$ & - \\
8 & Kuarsa & $\sqrt{ }$ & $\sqrt{ }$ & - & $\sqrt{ }$ & $\sqrt{ }$ & $\sqrt{ }$ & $\sqrt{ }$ & $\sqrt{ }$ & $\sqrt{ }$ & - \\
9 & Magnetit & $\sqrt{ }$ & $\sqrt{ }$ & $\sqrt{ }$ & $\sqrt{ }$ & $\sqrt{ }$ & $\sqrt{ }$ & $\sqrt{ }$ & $\sqrt{ }$ & $\sqrt{ }$ & - \\
10 & Korondum & - & - & - & $\sqrt{ }$ & - & - & - & - & - & - \\
11 & Sulfur & $\sqrt{ }$ & $\sqrt{ }$ & $\sqrt{ }$ & - & $\sqrt{ }$ & $\sqrt{ }$ & - & - & - & - \\
\hline
\end{tabular}

Tabel 7 Penampakan mikroskopis dan deskripsi mineral fraksi pasir yang ditemukan pada profil Tangkuban Parahu (TPR)

\begin{tabular}{|c|c|c|c|c|c|}
\hline No & Deskripsi Mineral & $\begin{array}{l}\text { Penampakan } \\
\text { Mikroskopis }\end{array}$ & No & Deskripsi Mineral & $\begin{array}{l}\text { Penampakan } \\
\text { Mikroskopis }\end{array}$ \\
\hline \multirow[t]{2}{*}{1} & Hiperstin $(\mathrm{Mg}, \mathrm{Fe}) \mathrm{SiO}_{3}$ & Perbesaran 20X & 7 & Biotit & Perbesaran 20X \\
\hline & $\begin{array}{l}\text { Warna hitam, kilap } \\
\text { kaca, kekerasan 6-6,5, } \\
\text { bentuk kristal } \\
\text { ortorombik, berat jenis } \\
\text { 24. }\end{array}$ & & & $\begin{array}{l}\mathrm{K}(\mathrm{Mg}, \mathrm{Fe})_{3}\left(\mathrm{AlSi}_{3} \mathrm{O}_{10}\right)(\mathrm{OH})_{2} \\
\text { Warna coklat kehitaman, } \\
\text { Kilap kaca, kekerasan 2,5, } \\
\text { berat jenis } 2,9-3,4 \text {, bentuk }\end{array}$ & \\
\hline
\end{tabular}

2 Diopsid $\mathrm{MgCaSi}_{2} \mathrm{O}_{6}$ Warna hijau kekuningan, sistem kristal monoklin, kilap kaca, kekerasan 6-6,5, Berat jenis 3,34, bentuk mineral anhedral

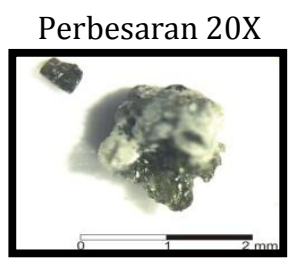

3 Ortoklas $\mathrm{KAlSi}_{3} \mathrm{O}_{8}$ Warna merah muda, sistem kristal monoklin, kekerasan 6, berat jenis 2,55, kilap kaca, warna goresan putih, bentuk sub-hedral granular.

\section{Oligoklas}

$(\mathrm{Na}, \mathrm{Ca})(\mathrm{Al}, \mathrm{Si}) \mathrm{AlSi}_{2} \mathrm{O}_{8}$ Warna: Tidak berwarna - putih, abu-abu, hijau pucat, kuning atau coklat, sistem kristal: blocky atau tabular; berat jenis: 2,64-2,68, kilap kaca, warna sebuk putih,
Perbesaran $16 \mathrm{x}$
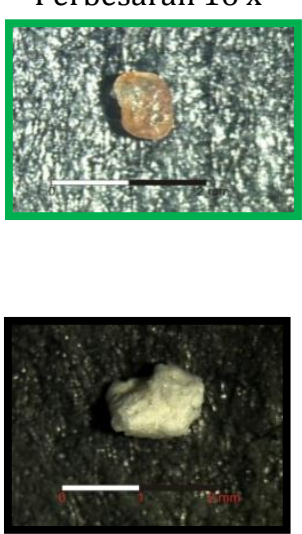
monoklin, bentuk mineral anhedral.

8 Kuarsa $\mathrm{SiO}_{2}$

Warna putih, kilap kaca, kekerasan 7, goresan putih berat jenis 2,65, belahan tidak ada, bentuk subhedral prismatik.

\section{Korondum $\mathrm{Al}_{2} \mathrm{O}_{3}$}

Warna merah bata, system kristal heksagonal, bentuk kristal prismatik, bentuk mineral subhedral, goresan putih, kilap adamantin, kekerasan 9, berat jenis

Perbesaran $20 \mathrm{x}$

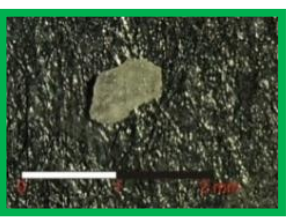

Perbesaran $16 \mathrm{x}$ 4,0-4,1.

10 Magnetit $\mathrm{Fe}_{3} \mathrm{O}_{4}$

Warna Hitam, goresan hitam, kekerasan 6-6,5. Berat jenis 5,2, kilap logam, Sistem kristal isometrik, bentuk subhedral massif halus.
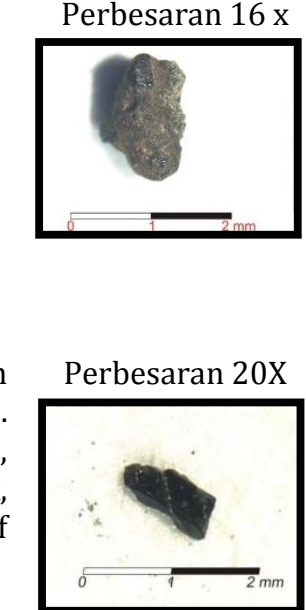


\begin{tabular}{|c|c|c|c|c|c|}
\hline No & Deskripsi Mineral & $\begin{array}{l}\text { Penampakan } \\
\text { Mikroskopis }\end{array}$ & No & Deskripsi Mineral & $\begin{array}{l}\text { Penampakan } \\
\text { Mikroskopis }\end{array}$ \\
\hline 5 & $\begin{array}{l}\text { Anortit } \mathrm{NaAlSi}_{3} \mathrm{O}_{8} \\
\text { Warna putih, kilap } \\
\text { kaca, kekerasan 6-6,5, } \\
\text { berat jenis 2,6-2,65, } \\
\text { sistem kristal triklin, } \\
\text { bentuk tabular, goresan } \\
\text { putih }\end{array}$ & Perbesaran $20 \mathrm{x}$ & 11 & $\begin{array}{l}\text { Andesine }(\mathrm{Na}, \mathrm{Ca}) \mathrm{AlSi}_{3} \mathrm{O}_{8} \\
\text { Warna putih susu, kilap } \\
\text { kaca, kekerasan } 6-6,5 \text {, berat } \\
\text { jenis } 2,6-2,65 \text {, sistem kristal } \\
\text { triklin, bentuk tabular, } \\
\text { goresan putih, bentuk } \\
\text { mineral subhedral }\end{array}$ & Perbesaran $20 \mathrm{x}$ \\
\hline 6 & $\begin{array}{l}\text { Hornblende } \\
(\mathrm{Ca}, \mathrm{Na})_{2-3}(\mathrm{Mg}, \mathrm{Fe}, \mathrm{Al})_{5} \\
(\mathrm{Al}, \mathrm{Si})_{8} \mathrm{O}_{22}(\mathrm{OH}, \mathrm{F})_{2} ; \mathrm{ke}- \\
\text { kerasan: } 5-6 \text {, berat je- } \\
\text { nis 2,9-3,4 warna hijau, } \\
\text { coklat kehijauan, coklat } \\
\text { dibedakan dengan mi- } \\
\text { neral mineral piroksen } \\
\text { dan biotit mika, }\end{array}$ & Perbesaran $20 \mathrm{x}$ & 12 & $\begin{array}{l}\text { Sulfur S } \\
\text { Warna kuning, goresan } \\
\text { putih, sistem kristal } \\
\text { ortorombik, kilap lemak, } \\
\text { kekerasan 1,5-2,5, berat } \\
\text { jenis 2,07, bentuk mineral } \\
\text { subhedral. }\end{array}$ & Perbesaran $20 \mathrm{x}$ \\
\hline
\end{tabular}

Mineral-mineral yang terdapat pada profil TPR dan PTH ini adalah mineral yang lazim dijumpai pada batuan beku (Best dan Christiansen, 2001). Abu hasil erupsi gunungapi merupakan salah satu produk batuan beku, sehingga mineral tanahnya merupakan mineral dari hasil lapukan fisika batuan tersebut. Mineral fraksi pasir pada berbagai horison tanah di profil TPR dan PTH ini dapat dikelompokkan menjadi mineral silikat dan non silikat. Berpedoman pada Plummer et. a.l (2003), mineral silikat ini dapat dikelompokkan menjadi kelompok piroksin (hiperstin dan dipsid), kelompok feldspar (ortoklas, plagioklas, anortit dan andesin), kelompok amfibol (hornblende), kelompok mika (biotit) serta mineral kuarsa. Mineral non silikat adalah oksida aluminium (korundum), oksida besi (magnetit) dan unsur tunggal (sulfur).

Mineral tersebut juga dikelompokkan menjadi mineral mudah lapuk dan sukar lapuk. Mineral mudah lapuk dapat dipedomani untuk menduga pelepasan cadangan hara dari hasil pelapukan, dan potensi hara pada tanah. Pramuji dan Bustaman (2009) menduga cadangan hara dari tanah di Kalimantan Timur dan dari mineral ortoklas, sanidin, hornblende dan mineral lainnya di tanah tersebut. Mineral pada profil TPR dan PTH ini merupakan mineral mudah lapuk yaitu hiperstin, diopsid, ortoklas, plagioklas, anortit, hornblende dan biotit. Mineral tersebut dalam unsur penyusun kimianya mengandung hara K (ortoklas, biotit, hornblende), Ca (augite, diopsid, hornblende, anortit, hornblende, oligoklas), Mg (hiperstin, diopsid, augit, hornblende, biotit). Mineral-mineral tersebut juga ada yang mengandung beberapa hara tanaman seperti diopsid dan hornblende yang mengandung Ca dan Mg. Mineral mudah lapuk tersebut dalam proses pelapukan kimianya akan melepas hara ke dalam tanah dan tersedia untuk tanaman. Tanah yang kaya akan mineral tersebut diharapkan juga kaya akan hara yang dibutuhkan tanaman.

\section{KESIMPULAN}

Mineral fraksi pasir yang ditemukan pada Andisol hasil erupsi G. Tangkuban Parahu dan G. Patuha adalah hiperstin, diopsid, biotit, ortoklas, oligoklas, anortit, hornblende, biotit, kuarsa, korundum, magnetit, dan sulfur. Mineral mudah lapuk dan menyumbang hara adalah hiperstin, diopsid, biotit, ortoklas, oligoklas, anortit, hornblende, biotit dan kuarsa. Hara yang dapat dihasilkan dari pelapukan mineral tersebut adalah $\mathrm{Ca}, \mathrm{Mg}, \mathrm{K}$ dan S.

\section{Ucapan Terima Kasih}

Penulis mengucapkan terima kasih kepada Hamdani, Aditio Wibowo Djohar dan 
Rio Kurniawan yang membantu sampling di lapangan, serta Ahmad Afandi yang membantu dalam analisis mineral.

\section{DAFTAR PUSTAKA}

Ande, I., and B. Senjobi. 2010. Lithologic discontinuity and pedogenetic characterrization on an aberrant toposequence associated with a rock hill in South Western Nigeria. International Journal of the Physical Sciences, 5(5). 596-604.

Arifin, M. 1994. Pedogenesis Andisol Berbahan Induk Abu Volkan Andesit dan Basalt pada Beberapa Zona Agroklimat di Daerah Perkebunan Teh Jawa Barat. Disertasi Doktor. Institut Pertanian Bogor. 202 hal.

Badan Perencanaan Daerah (Bapeda). 2008a. Peta Jenis Tanah Kabupaten Bandung, Jawa Barat, Skala 1 : 125.000. Badan Perencanaan Tata Ruang dan Lahan. Bandung.

Badan Perencanaan Daerah (Bapeda). 2008b. Peta Penggunaan Lahan Kabupaten Bandung, Jawa Barat, Skala 1:125.000. Badan Perencanaan Tata Ruang dan Lahan. Bandung.

Badan Perencanaan Daerah (Bapeda). 2008c. Peta Kemiringan Lereng Kabupaten Bandung, Jawa Barat, Skala 1:125.000. Badan Perencanaan Tata Ruang dan Lahan. Bandung.

Badan Perencanaan Daerah (Bapeda). 2010. Peta Iklim Kabupaten Bandung, Jawa Barat, Skala 1:125.000. Badan Perencanaan Tata Ruang dan Lahan. Bandung.

Best, M.G. and E. H. Christiansen. 2001. Igneous Petrology. Blackwell Science, 458 $\mathrm{pp}$

Devnita, R., Arifin, M., Salim, E.H., Sudrajat, H., Hudaya, R., and Van Ranst, E. 2010. Soil developed on volcanic materials in West Java, Indonesia. International Journal of Arts and Sciences, 9, 180-192.

Hardjowigeno, S. 2003. Klasifikasi Tanah dan Pedogenesis. Akademika Pressindo, Jakarta. 354 hal.
Koesmono. 1976. Peta Geologi Lembar Sindangbarang, Jawa. Dir. Geologi. Dep. Pertambangan. R. I. Bandung.

Mange, M. A. and H. W. F. Mauver. 1992. Heavy Minerals in Colour. Chapman and Hall. London. $147 \mathrm{p}$.

National Soil Survey Center (NSSC). 2002. Field Book for Describing and Sampling Soils Version 2.0. Natural resources Conservation Service. United State Departement of Agriculture. 219 p.

Parfitt, E. A., and L. Wilson. 2008. Fundamentals of Physical Volcanology. Blackwell Sci. Ltd. Australia. 210 pp.

Plummer, C.C., D. Mc. Geary, and D. H. Carlson. 2003. Physical Geology, ninth edition. Mc. Graw Hill. New York. 574 pp.

Pramuji dan M. Bastaman. 2009. Teknik analisis mineral tanah untuk menduga cadangan sumber hara. Buletin Teknik Pertanian 14 (2): 80-82.

Puslitbangtanak, 2001. Atlas Sumberdaya Tanah Indonesia Tingkat Eksplorasi, skala 1:1.000.000. Puslitbangtanak, Bogor.

Silitonga, P. H. 2003. Peta Geologi Lembar Bandung. Departemen Energi dan Sumber Daya Mineral

Soil Survey Staff. 2014. Keys to Soil Taxonomy. $10^{\text {th }}$ ed. Natural Resources Conservation Service. $332 \mathrm{p}$.

Sudradjat, A. 1992. Gunungapi dan Gempabumi. Jakarta. 164 hal.

Sudradjat, A. 2009. The Development of Volcanologic Investigation in Indonesia. Universitas Padjadjaran Press. Bandung. 239 hal.

Van Reeuwijk, L. P. 1992. Procedure for Soil Analysis. Fourth Edition. ISRIC. Wageningen. The Netherland. $56 \mathrm{p}$.

Weindorf, D. C., S. Chakraborty, A. Abdalsatar, L. Paulette, G. Corti, E. Michéli, D. Wang, B. Li, T. Man, A. Sharma and T Person. 2015. Lithologic Discontinuity Assessment in Soils via Portable X-ray Fluorescence Spectrometry and Visible Near-Infrared Diffuse Reflectance Spectroscopy Soil Science Society of America Journal. 
